Forum 2016 $31: 438$

DOI 10.1007/s12312-016-0138-1

Online publiziert: 29. September 2016

c) Springer-Verlag Berlin Heidelberg 2016

NIEDERSÄCHSISCHE

KREBSGESELLSCHAFT E.V.

Niedersächsische Krebsgesellschaft e.V., Hannover

\title{
Schmutziger Sport für eine saubere Sache
}

\author{
Schlickschlittenrennen „Wältmeisterschaft" 2016 \\ als Benefizveranstaltung
}

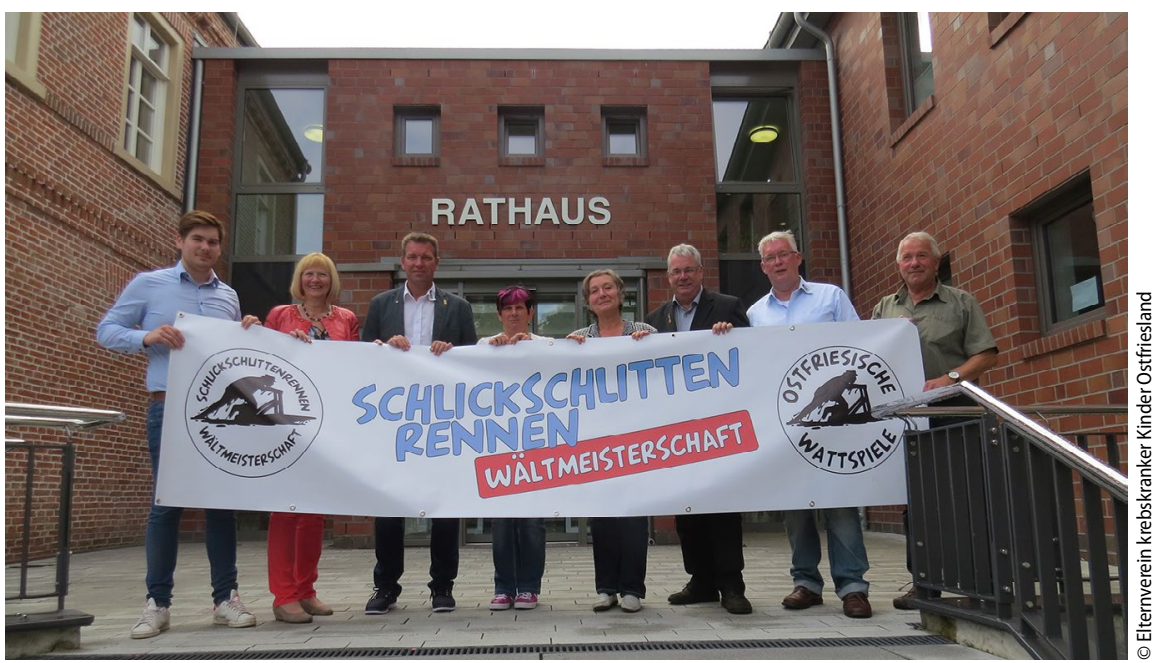

$\Delta$ Die Organisatoren mit Vertretern der Niedersächsischen Krebsgesellschaft und des Elternvereins krebskranker Kinder Ostfriesland

Wattfußball, Aalsprint und „Watt' n Achter" gegeneinander an und sanken dabei bis zu den Knien in den Schlick. Um die Mannschaften besser unterscheiden zu können, erschienen die Teilnehmer wie in jedem Jahr wieder mit ausgefallenen und farbenprächtigen Kostümen. Prämiert wurden nicht nur die besten Teams und

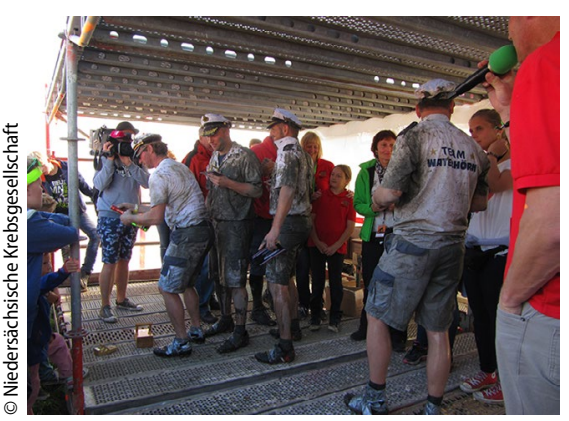

$\Delta$ Siegerehrung die originellsten Kostüme; auch das langsamste Team erhielt einen Ehrenpreis. Abgerundet wurde die Veranstaltung durch ein buntes Rahmenprogramm mit einem Kinderfest, dem Auftritt einer regionalen Sambagruppe und einer Tombola, bei der es einen hochwertigen Strandkorb zu gewinnen gab.

Mehr Informationen und weitere Fotos unter www.schlickschlittenrennen.de

\section{Kontakt}

\section{Dr. Bärbel Burmester}

Geschäftsstellenleiterin

Niedersächsische Krebsgesellschaft e.V.

Königstraße 27, 30175 Hannover

Tel.: 0511 - 3885262

service@nds-krebsgesellschaft.de

www.nds-krebsgesellschaft.de
$\Delta$ Die Zuschauer warten auf den Beginn der Wettkämpfe 